\title{
Mapping: Coming to Grips with Educational Landscapes
}

\section{Introduction}

Mapmaking is an old and ubiquitous human impulse; a basic form of human communication. Maps are not only graphical representations of an environment, but powerful everyday metaphors to convey ideas of clarification, coherence, plotting information on paper. The basic concept in mapping is that of spatial relatedness, an awareness of relations in space - evidently useful in terms of (relative) location and distances. But most other things can be analogized or equated to space, and that includes, we argue, scientific disciplines and fields of inquiry. Note the spatial whiff of the term "field".

Mapmakers, as John Wilford (2000) points out, must decide what to show, how to show it, and what not to show, and for what reasons. They deconstruct a part of the world and then reassemble it. The first known mapmakers, the Babylonians, mapped with accuracy what they knew: city walls and property boundaries. The lands beyond theirs, which they did not know, they chose to ignore or fabricate. Maps are constructed to do something for us. Our initial hypothesis is that maps of scientific disciplines and fields of study have two basic purposes: to provide an overview of the "elements" that the discipline or field consists of and indicate how these are connected, and to separate the mapped field from the "lands beyond". As the Babylonian case indicates: no map can be relied on to tell the whole truth about its landscape, due to limitations in knowledge, restrictions imposed by the map format and by the intended purpose of the map, and in our case the fluid and shifting character of the landscape to be mapped.

We shall in this paper discuss disciplinary mapmaking and its challenges. Our purpose is threefold. Mostly confining ourselves to the case of Norway, we shall discuss the following topics: First we look at different historical attempts to represent education understood as a discipline, in terms of a model or map of the discipline, from the 1920 s to date. Second we inquire into the historical changes of the landscape supposedly mapped, 
using empirical sources. For clarity of exposition we look at the selected maps first, and then the landscape. The state of the discipline/field at any given time does not dictate what a map of it should look like; still the map selection hints at a certain development in disciplinary mapmaking. Our landscape inquiry basically shows that the discipline/landscape has expanded immensely over the past 30 years or so; it has outgrown its original disciplinary boundaries and structures and turned into what is better understood as a field. This resulting field can be characterized as fragmented, as having no unity, with porous outer boundaries and content in constant flux. This is a difficult position to be in for any field. Not only are the old maps no longer adequate to navigate the landscape, but fields without marked boundaries and key topics are more vulnerable to external/political involvement. That brings us to our third topic: What do we do in such a situation? No doubt many responses are possible; we shall inquire into a select few. For various reasons the field cannot return to a tidy disciplinary state. But other forms of boundary-work are available, for example practical syntheses and theoretical integration. The diagnosed flux is a double-edged sword. On the one hand it leads to fragmentation and identity problems, on the other it may open up for unusual perspectives and general renewal.

The concepts of maps, fields and disciplines will be expounded as we go along, but a short introductory sketch is in order. We take it there is a difference between disciplines and fields that to some extent is worthy upholding, despite not being very clear-cut. There are competing views of what disciplines are and what they do. Paul Trowler (2014) argues that much of the literature on the nature of disciplines and fields has adopted what he calls a "strong essentialist position"; a position that at least incorporates the view that a discipline should possess a unique set of characteristics, a specialized vocabulary, a systematic research strategy, perhaps specialized criteria of validity, and a clearly delineated phenomenon (subject) of interest that has a definable and necessary character. The characteristics together, Trowler suggests, are supposed to mark a discipline as being itself - that is, education, and not, say, psychology. In Trowler's judgment strong essentialist accounts of disciplines are reductionist; they flatten out internal differences, occlude complexity and are conceptually limiting. The strong essentialist view is normative in character rather than descriptive - this is arguably 
what one thinks an academic discipline should look like. Not all viewpoints in the literature express a strong essentialist position, however. For example, Rita Hofstetter (2012) describes education as a "pluridisciplinary field" and argues that it has been so since its first inception, largely due to the subject of interest, which on Hofstetter's view is educational action. This subject crosses other disciplines and pluridisciplinarity is therefore called for. Pluridisciplinarity is a useful term in that it encompasses both multidisciplinary, interdisciplinary and transdisciplinary perspectives.

Next, a brief note on different ways of conceptualizing the relationship between discipline and field. If conceived of as a continuum along the dimensions of order and identity, disciplines would find themselves near the orderly, unified, coherent, kepttogether end of the continuum where the identity of the subject is clear. Fields would find themselves near the disorderly, fragmented, diverse or hybrid end where it is much harder to say what the field encompasses, where the boundaries are, and what the subject actually is. There is no exact tipping point on such a continuum where a discipline becomes a field. If understood as a part-whole relation, we get a picture of fields as constituted by various sub-disciplines. This is an attractive picture, structurally different from the continuum picture, but allowing the same characterizations of disciplines as having boundaries and a clearly identified subject, and fields as being more disorderly simply because they are bigger and encompass different disciplines which sit more or less well together. This is our preferred understanding. It is also perfectly compatible with Hofstetter's view. When a field is pluridisciplinary, it consists of several disciplines; which means that the disciplines constitute the parts and the field constitutes the whole.

Finally, a brief note on terminology. In Norway we currently have three different labels in play. We have pedagogikk, which denotes the discipline of education (and thus should not be translated into pedagogy). Then there is education research (in Norwegian utdanningsforskning) which denotes research done on schools and various educational topics but from perspectives external to education. Lastly we have educational sciences (in Norwegian utdanningsvitenskap), which include the traditional discipline of education, subject didactics, professionally oriented educational research, special education, etc. 


\section{Norwegian maps of education: a selection}

Academic research today is global. Rudolf Stichweh claims that this global interconnectedness should not be understood as a worldwide community of researchers sharing normative and cognitive presuppositions, but rather as a proliferation of research communities which organize "the social and cognitive space of science in a way which is incompatible with the boundaries of national scientific communities" (1996, p.332). All the same we begin with a national perspective, leaning on Hofstetter, Fontaine, Huitric and Picard, who argue that while research (including journals, associations and conferences) indeed is becoming increasingly international, higher education systems (including structure of curricula and academic career paths) "exhibit strong national particularities" (2014, p.874). In addition, maps are generally valuable to historians because interpretations of place changes over time. In our case different maps not only speak to different understandings of the landscape being mapped; they also illustrate a changing, growing and shifting landscape and such growth is due to both national particularities and international trends. Norwegian maps may provide interesting comparisons with other national maps.

Disciplinary landscapes are fluid - a fact which makes mapping even more of a challenge. Disciplinary mapmakers today face the same problem as the old Babylonians did: what sort of qualities should maps of disciplines and fields possess, that they accommodate the landscape in a useful way? Let us look at some examples.

\section{Helga Eng's map, 1926}

It is hardly ever self-evident how to pinpoint the beginning when one wants to trace historical developments. We choose to begin in 1926, with the publication of a review article by Helga Eng called Norsk opdragelsesvidenskab 1900-1925 [Norwegian educational science 1900-1925]. The review sums up contributions from Norwegian scholars over a period of 25 years and presents the following topical map:
A: Systematisk pedagogikk
Systematic educational theory
B: Pedagogisk psykologi
Educational psychology
C: Pedagogikkens historie
Educational history 

D. Didaktikk
Didactics
E: Skolehygiene
School hygiene

Some comments are in order. First, it may be a bit of conceptual stretch to call this review a map since there is no obvious spatial relatedness involved. Even so, it does contain constituent domains and we choose to view it as an early mapping effort. We get no specific sense of how the domains are related to and/or influence one another. The "ranking" A-E does not speak to relative importance of the domains; textual evidence rather suggests that the map is simply meant to suggest what the constituent elements of the discipline of education are. Second, the map shows an early $20^{\text {th }}$ century pattern of differentiation. Eng presented it more than a decade before the key institutionalization of education in Norway; the establishment of the Department of Educational Research at the University of Oslo in 1938. This makes the 1926 map more remarkable than it seems at first sight, since disciplines form and develop when they achieve an institutional status that brings chairs, positions, outlets and funds, professors and students who study and specialize in the discipline (Hofstetter et.al, 2014). Helga Eng became the first professor of the new department and served 12 years as department head. Third, any student of education will notice domain $\mathrm{E}$, which was important in those days but which disappeared after WW2. The other domains are still visible today as relatively distinct domains, albeit with shifting balances during the nearly 100 years that have passed since the publication of Eng's map.

Fourth, we would like to draw attention to domain D; didactics, the inclusion of which in the disciplinary map suggests that both theoretical and practical dimensions of education and their synthesis were of scientific concern. This seemingly innocuous feature has several ramifications. It points to the presence of two differing but interrelated landscapes; an "internal" disciplinary one and an "external" professional one. The first landscape is largely epistemological and concerns education as a distinct academic discipline; its constituent domains and their unification or styles of integration. The second landscape concerns the practically oriented, professional and out-reaching dimension. Eng's map indicates that education as a discipline is not only epistemically constituted around a (more or less) well delineated subject, but that social, practical and 
political demands influence the constitution of the discipline. Hofstetter (2012) describes educational sciences/disciplines as being hybrid and plural from their inception, and Eng's inclusion of four different theoretical domains and one professional domain surely testifies to this - we might even say that it is doubly hybrid, with two partly overlapping interacting landscapes and a pluralist disciplinary landscape.

\section{Reidar Myhre's map, 1980}

We make a temporal leap and look at Reidar Myhre's map (1980). This map, we dare say, is the single most influential map of education in Norway. Its visual appearance is striking. The constituent domains are carefully laid out in a circle as demarcated territories and their mutual interconnectedness is represented by double-headed arrows. At the center Myhre has placed the twin terms didactics and theory of upbringing (Erziehiungswissenschaft) and the double-headed arrows between center and constituent domains signify mutual influence and interplay.

Fig. 1. About here

This map is graphically truly excellent and nicely illustrates the communicative power of maps. It is clearly constructed on the principle of spatial relatedness and easily communicates domains, center, periphery, interconnectedness and interplay. No unnecessary graphic embellishments are included. Its sheer qualities as a map thus allow it to communicate information about its landscape much more effectively than did Eng's map. Incidentally, this might be one of the reasons for the longstanding popularity and influence of Myhre's disciplinary map. It gives much information at one glance.

So what can we infer from Myhre's map? Several things spring to mind. First, the representational form itself. The position of didactics and theory of upbringing in the center indicates that they are not really to be understood as constituent domains on a par with the other six domains. Rather they directly represent the main subject of the discipline of education; namely schooling and upbringing. The double-headed arrows between center and periphery indicate that the various domains making up the periphery shall make their own specialized contributions to the center, and the center in turn brings unity and integration to the domains. Second, as a corollary to the first point, education is 
unequivocally defined as a practically oriented discipline. Educational practice, in the form of schooling and upbringing, takes center stage, and the constituent domains are at its service. This map thus suggests a fairly clear identity for education as a discipline.

Third, the diversification of constituent elements or domains. Four of the domains are the customary foundational disciplines of pedagogy: philosophy, history, psychology and sociology of education. Inclusion of theology is best understood, we think, as a result of Myhre's personal views (he was a devout Christian) - it never gained support as a general foundational discipline of pedagogy despite the close historical connections between church and school. This diversification suggests that the mapped landscape has changed. Two domains have disappeared; systematic pedagogy and school hygiene. They have been replaced by philosophy, theology, sociology of education and comparative education.

There is no doubt that Myhre takes himself to have painted a comprehensive picture of education as a discipline. Since Eng published her map there has been a certain pressure of diversification from the inside which has been met in the new domains that have been included in his map, and two old ones that have disappeared. Theories of schooling and upbringing at the center indicate that the map traverses both internal and external landscapes; the discipline and the profession. Myhre probably held much the same view of the identity of education that Eng did, but his map communicates it much clearer than hers. Education is constituted of foundational disciplines in the service of practice. It is fundamentally a hybrid domain, with a plurality of disciplines which are thought to hang together because they all contribute to the same central element. Theories of schooling and upbringing are thus given the task of providing unity to or integrating the constituent disciplines.

\section{Ola Stafseng's map, 2011}

Again we make a leap in time. While Myhre's map can be viewed as a reorganization and diversification of Eng's map, Stafseng's map provides a sharp contrast. We shall inquire into changes in the landscape that necessitate new maps in the subsequent section of the paper, but a few initial remarks are in order. Myhre, in constructing his map, could use neighboring disciplines (philosophy, psychology, etc.) as his main criterion for deciding 
on and organizing the constituent domains in his map. By 2011 that is no longer a feasible strategy. As Stichweh (1996) suggests, the problem spaces of sciences and disciplines are progressively decomposing into smaller, more fragmented and more specialized areas. To draw a map you need criteria for what to include and what not to include. The time-honored foundational disciplines still exist, but today education has diversified into a huge (and growing) number of topical areas. For example preschool education, university education, workplace learning, science education, reading instruction, language didactics, governance, mathematics didactics, informal learning, special education - all of them with more specific sub- and sub-sub-categories (Kvernbekk, 2001). What, then, is a mapmaker to do, in the face of such disintegration and disorder?

One option is to do what Ola Stafseng does, namely waive any ambitions of providing a comprehensive, detailed, spatially laid out map of education and instead drawing a more abstract or metaphorical map. Here is Stafseng's map (2011, p.92):

Fig. 2 about here

This is also a map. It just does not employ the standard features of maps and is intuitively much less legible than Myhre's map. No domains are laid out spatially (they are not even mentioned), no boundaries are drawn to suggest relative locations, central and less central topics, no arrows are included to suggest interaction across boundaries. To be sure, Stafseng has great ambitions for his proposed map; he makes it clear that he thinks most educational discourses could be accommodated by it. But how?

This map consists of three axes: time, space and an educational continuum ranging from integration to individualization. Time refers to organization of both children and content, in terms of age, grades, maturity, development, progression and the problem of whether (planned) subject progression matches the cognitive and social development of children. Space refers to institutional order and flexibility and to how much of life the educational institutions should cover - which parts of life should be education-free, as it 
were. The third axis, which is represented by the diagonal on the map, is a continuum meant to capture the key tension in socialization and upbringing as well as in teaching and self-formation between individualization and integration, individual and society, emancipation and autonomy balanced against legitimate community concerns. The addition of this third axis makes the map three-dimensional, Stafseng argues.

What does this map communicate? That is perhaps hard to say. As mentioned above, it uses none of the common or expected parameters of mapmaking - the idea of spatial relatedness is hard to find in this map. The old foundational disciplines are conspicuously absent, as are the topical, specialized areas that have emerged since Myhre published his map. Stafseng's map does not exhibit a center of gravitation like Myhre's map and yet it communicates an idea about the subject of education; namely that it somehow encompasses individuals, contents, institutions and society, and that the relevant dimensions to study concern temporality, space and degree of integration.

To stay with the mapping metaphor, this map makes use of coordinates rather than concrete graphic content. We could say that it maps principles for mapping a given landscape, rather than mapping the landscape itself. The principles reflect Stafseng's academic orientation; they draw on social theory, socialization and education and not on traditional educational individualism. The map illustrates the process and power of abstraction. By removing itself one step from concrete content the map, perhaps paradoxically, is able to accommodate many diverse educational topics, theories and discourses, like Stafseng suggests, as long as these fall under the main dimensions depicted in the map. Moreover, the dimensions allow comparison of topics, e.g. as to where differing viewpoints find themselves on the integration dimension. As such, an abstract map of this kind might help students develop an overview of and a judgment of the relative qualities of different educational theories.

\section{Interlude: Ewald Terhart's meta-map, 2016}

Like Stafseng's map, this is not a spatial lay-out of a landscape but a highly abstract map. It can be understood as a response to the state of the landscape: Terhart describes education as a fluid terrain, hinting that not only is the supposed landscape fragmented 
and without unity, its interior is in constant flux and its outer boundaries are shifting. Drawing maps of fluid landscapes is thus a futile exercise. Terhart's map serves a different purpose, and that is why we call it a meta-map. This map gives you the main coordinates, the parameters you orient yourself along if you wish to draw a disciplinary map.

Fig. 3 about here

The meta-map is three-dimensional. Taken together the dimensions create a systematic space in which any national institutional form of education can be placed, and thereby compared to other forms. It does not tell you which sub-disciplines or topics education consists of. It provides you with a tool for navigating your local/national landscape, for imposing order on massive amounts of details and, thereby, for making possible international comparison of mapping attempts. At this point we have therefore transcended our national context. The meta-map is international.

\section{A changing landscape: Layers of educational research in Norway}

We return now to the case of Norway. The following exposition is intended to illustrate two points. First, and most importantly, the kind of changes and growth that academic landscapes can undergo - we outline three broad changes. Second, that any disciplinary mapping is complicated because it is impinged on not only by internal disciplinary forces, but by political decisions, reforms and institutional changes. In addition, description of changes in the landscape itself is made difficult because of shifts in conceptualization of research in and on education.

\section{Institutionalization of a university discipline}

Helga Eng's map from 1926 represents an early institutionalization of education as an academic discipline. As a professional field of knowledge, however, pedagogy (understood as a practically oriented form of knowledge) is much older and can be found in teacher seminars from the 1840s and onwards. The Department of Educational 
Research at the University of Oslo was established in 1938 and educational psychology came to dominate both research and courses from the very beginning. Thus, while Eng's map may yield an accurate picture of the Norwegian realm of education from 1900 to 1926 , it is an open question how accurate it is concerning the period after the key institutionalization of education in Norway. Her map depicts all five domains as equivalent.

In the period up to around 1970 the boundaries between discipline and professional field, between basic and applied research, were strong. Thus, in keeping with the general research hierarchy after World War II experimental psychology was ranked on top and professional and practical knowledge was seen as less important and less interesting for research (see e.g. Jarning, 2016, Tröhler, 2016). Educational psychology was able to hold on to its dominant position for decades, among other things because it had a stable external source of funding of basic research, one of five forerunners of the current Research Council of Norway (RCN). Expressed in sheer figures: of a total of 9.5 million NOK given in research grants nationwide between 1950 and 1970, more than 2.5 million NOK went to the Department of Educational Research alone (Helsvig, 2003).

\section{A multidisciplinary consolidation}

From around 1970 a binary system of higher education emerged, with the universities (then four of them) on the one hand and a high number of regional colleges on the other. With very few exceptions the colleges had no access to systematic research funding. We can observe two major intellectual changes, both amply illustrated in Myhre's map: a broadening of the circle of disciplines and a gradual loss of hegemony of educational psychology. But the boundary and division of labor between universities and colleges persist: basic research in the universities and professional education and applied research in the colleges (albeit with a few exceptions).

The proliferation of sub-disciplines and the concomitant differentiation of research agendas were partly due to internal changes, new ideas and new perspectives being developed. This is for example illustrated in a festschrift to a prominent professor ${ }^{1}$

\footnotetext{
${ }^{1}$ Professor Hans Jørgen Dokka represented a broader approach to research in education, including historical and curricular issues. He combined a marginal intellectual position in the discipline with a broad recognition as professional expert and leader of a major reform commission.
} 
at the Department of Educational Research (Befring et.al, 1973), which contains chapters on historical topics, philosophy of science, philosophy of education, as well as the budding field of curriculum research - and none on educational psychology. The discipline of education thus developed toward a pluridisciplinary structure. This profound shift was the main message in a 1986 "state of the art" report to the Research Council: the understanding of education as a discipline had changed; the main reason being the fact that psychology had lost its status as the dominant sub-discipline (Vislie, 1986).

But arguably also changes in funding policy and governance contributed to the diversification of education. One thing is that in 1968 the (then) Research Council for basic research was reorganized and funding proceeded according to a different categorization: education had up till then been grouped with psychology and youth studies, but was now integrated in the wider area of social sciences (Helsvig, 2003). This encouraged interdisciplinary research agendas and different kinds of research questions. Another thing is that other institutions were established, for example the Council for Primary Education, which could fund more practical research. As of 1970 the Ministry of Education itself had a budget item devoted to school research. One example of educational research being funded by new agencies, in this case the Council for Primary Education, is the so-called Lofoten Project; an action research project aimed at developing a form of schooling that was more relevant to the local community. Hence the project was explicitly critical of the existing national curriculum, which ignored local knowledge and tradition, and of a school system which prevented pupils from taking part in the local work life (Høgmo, Solstad \& Tiller, 1981). On the whole we might say that more diversity in sources of funding led to more diversity not only in the kind of knowledge that was produced, but also in possible welfare contributions.

As of 1970 the discipline is back to its previous pluridisciplinary structure - as found in Eng's map - but this time also encompassing not only Myhre's suggested subdisciplines (however except theology), but also curriculum theory and classroom research. In addition, a new generation of philosophers appears on the scene, engaged in educational and social issues. A sub-discipline called social education is established, based on social theory and the new sociology of schooling of the 1960s and 1970s. 


\section{An expanding hybrid landscape}

During our third tentative period, which stretches from the 1990s and up to date, the internal differentiation process has accelerated; not in terms of a growth in number of sub-disciplines, but a more varied form of growth.

The terms educational sciences and education research are introduced and put into play. The result is a rapid growth of multi- and interdisciplinary research and scholarship, with a concomitant growth in exchanges between academic, professional and policy-oriented interests and areas - the proliferation of topics, problems, questions and perspectives is staggering. Some of these new topics are hybrid in character. For example, general didactics and political science join up in issues concerning governance and policy; education and law join up in issues concerning the juridification of education; sociology and education join up in issues concerning effects of schooling on social equality. These are true hybrids in that they do not belong exclusively to one discipline, but to (at least) two. The boundaries are porous, as Terhart suggests. Subject didactics is another case in point - a sub-field that has enjoyed a great expansion in recent years. Didactics moves into the subjects, that is, into languages, literature, mathematics, etc. to interact with their nature and we get mathematics didactics, religion didactics, etc.

Subject didactical topics are hybrid: they are neither pure subject nor pure didactics, but both, crossing the boundary between the system of disciplines and the teaching profession.

This massive expansion and diversification of the field of education was greatly facilitated by a national college reform. The strict binary policy described above was dismantled. In 1995 common legislation for all public higher education institutions was implemented, and with that came a general mandate for general research for the colleges, including the teacher education colleges. In a national evaluation of educational research (RCN, 2002) the inclusion of new institutions shows up not least in the increase in number of researchers in the field. In 1985 there were 82 researchers with a degree in education employed in the universities and 16 in certain colleges. In 1999 the number is 481. The total number of researchers doing education research in 1999 was 972 (this includes researchers who do not have a degree in education, for example sociologists or political scientists), and almost $70 \%$ of them were involved in teacher education. This 
accounts for much of the growth in subject didactics research. In 2015 the number of people doing education research had grown to 2914,1753 of them employed in colleges (Gunnes et.al. 2017). The same report also documents the varying pluridisciplinary profile of education research in 2015 in the three large subsectors: universities, colleges, and other research institutes. The three key areas of educational sciences represented this year more than $80 \%$ of all research on education in the universities, almost $80 \%$ in the professional colleges, but only $20 \%$ in the institute sector (p.87). In universities the discipline of education made up $40 \%$ of the research volume and subject didactics $30 \%$, while subject didactics was the largest sub-area regarding research done in teacher education institutions.

Today, arguably, education research is dominated by professional topics and questions, and the discipline of education has all but lost the distinctive university discipline features it had between 1950 and 1990. The internal diversification has been enormous, and the once clear hierarchy between discipline and professional field is hardly visible anymore. This is the landscape that Stafseng faced when he made his map, and one can well understand his resolve to use a different set of principles altogether in constructing his map. Neither Eng nor Myhre would probably have recognized the current version of the field they knew. We thus come to the same general conclusion as Terhart, even though he speaks about Germany. We can no longer talk about a discipline in the traditional sense of the term, let alone an essentialist understanding of it, as described by Trowler. We have a field. The internal structure of this field is unstable, the outer boundaries are fuzzy and porous, and any disciplinary map is likely to be contested.

\section{Coming to grips with fluid, boundless landscapes}

What is it like for students to enter a field that is described as pluridisciplinary and fluid? We might also describe it as boundless. The picture is that of a field that is unwieldy, disorderly, fragmented, polyphonic, hybrid, and that keeps growing, changing, shifting. How can students develop a familiarity and a feel for the identity of the subject they are studying, a sense of the whole and what (if anything) keeps it together? We have argued 
that no comprehensive, graphically communicative maps are possible to draw anymore, so what can we do to help students navigate the field?

As a prelude to our brief inquiry into possible ways of coming to grips with fluid landscapes, let us invoke Lewis Carroll's paradox of the complete map. In the story Sylvie and Bruno Concluded we meet Mein Herr, who discusses the art of map-making with the author. How large should maps be to be useful? The author suggests six inches to the mile, to which Mein Herr proudly replies that in his country they made a map on the scale of a mile to the mile, but that using it presented them with a problem: "It has never been spread out, yet," said Mein Herr, "the farmers objected: they said it would cover the whole country and shut out the sunlight! So now we use the country itself, as its own map, and I assure you it does nearly as well" (Carroll, 1988, p. 557). The "nearly", we surmise, concerns the obvious usefulness of information about relative location and distances that a map gives you. The parallel to disciplinary maps is however not perfect, among other things because disciplinary landscapes change so rapidly that maps quickly become obsolete.

One of David Bridges' worries about educational research is that its current state of fluidity and fragmentation makes impossible what Robert Merton called organized skepticism (Bridges, 2006). Only a discipline, with its epistemic rigor and rules, can provide a home for organized skepticism. If Bridges is correct, what can we do to help the situation? Different things, we suggest. Let us begin by introducing the term boundary-work, a cousin of the demarcation problem (Gieryn, 1983). Gieryn locates boundary-work primarily at the intersection of science and non-science, and argues that practicing scientists employ various strategies to distinguish their own work from other intellectual activities. But boundary-work also applies to demarcations of disciplines and fields within science. In fact, the term "discipline" itself serves to demarcate a certain academic territory, with its associated bodies of knowledge, privileges and responsibilities. Any discipline must be able to maintain the boundaries to neighboring disciplines, lest they intrude and encroach upon the territory. The (perceived) identity of an academic field does not only depend on a unity of subject, demonstrated by Myhre's map, but also on what the field is not. How does education fare in this respect? To inquire into that question, we look at internal and outer boundaries. First, Hofstetter's term 
pluridisciplarity clearly presupposes some form of internal boundary-work to keep the constituent disciplines apart. Indeed, education seems to differ from other fields in that it traditionally harbors neighboring disciplines in its midst and in the UK tradition even calls them foundational (psychology, philosophy, history, sociology). Thus, the outer boundary does not shut other disciplines out; rather internal boundaries are constructed to depict how they contribute to the specific subject matter of education, as illustrated by Myhre's map. Second, one can ask whether there exists an outer boundary today. At best it is a highly porous one. The field rather seems to be a territory very open to migration from new tribes, parts of other fields move into education (e.g. sociology, economy, the various subjects in subject didactics), very little boundary-work seems to be happening. Former social scientific and humanistic fields overlap, encroach on one another's territories, melt into one another. The landscape we navigate is hybrid and fluid and the old maps are (perhaps) reduced to puzzling antiquities and no longer helpful.

Below are some suggested strategies for navigating a fluid landscape and for combatting fragmentation and creating what might be called "pockets of order". We do not aim at a well-organized, orderly field, but rather a fluid field with pockets of order and places where organized skepticism can yet flourish.

\section{Terhart's meta-map revisited}

Terhart's map is not geared to dispersed order, but to overview and comparison. You can relate (selected parts of) your fluid landscape to the parameters and get a big picture of how it fares: to what degree is it autonomous? Does it have constituent disciplines? Are professionalization issues included? How is this compared to others? We see that even Terhart's meta-map makes implicit reference to boundary-work. First, the disciplinarity dimension and the professional dimension indicates a boundary between what is commonly called basic and applied, which may be upheld in some contexts and obscured in others, for example in demands that research be practically relevant. As Gieryn (1993) points out, researchers sometimes employ various boundary-work strategies to exclude other researchers, claiming to represent the more important or central parts of the field, or claiming the field for themselves altogether. Second, the same mechanism might occur within e.g. the disciplinarity dimension, say in establishing the prestige of certain topics 
at the expense of others, maintaining sub-disciplines, or simply separating types of topics. Third, Terhart's map also suggests a form of outer boundary-work. Education is a case in point - on the one hand the landscape has grown and the field has thereby expanded its expertise into ever new domains, topics and occupations, on the other hand it is vital to keep one's autonomy in the face of e.g. government-steered research programs.

\section{Practical syntheses}

Practical syntheses are attempts at creating unity and coherence in the knowledge base of a profession. They are particularly interesting in our context here because they explicitly straddle both internal and external landscapes as well as the traditional discipline and the profession. The term was coined by the Norwegian philosopher Harald Grimen (2008).

The sources of professional knowledge are heterogeneous and theoretically fragmented, Grimen argues, and the various constituent elements are integrated in the form of a practical synthesis. The synthesis is practical, as opposed to theoretical, because the impetus for integration comes from the demands of practice. That is to say, professional practitioners and their educators produce local pockets of epistemic order by bringing different types of information into connection with one another, forming a professional repertoire that builds a coherent basis for action.

Grimen's concept thus addresses the problem at hand: how to handle elements that are heterogeneous (because they come from different sources) and weakly integrated (because their internal coherence is weak or perhaps even non-existent). A practical synthesis is a meaningful whole. Different pieces of knowledge, theoretical or experiential, are made to hang together as parts in a whole because they are brought together by the demands of practice. The selection of elements is based on judgments of their relevance to the task - and it is the task in question which creates the basis for the type of unity that professional knowledge enjoys, Grimen argues. The unity produced by this kind of boundary-work is local, and perhaps not for repeated use if the circumstances are extraordinary.

In Norway, during the last decade, "practical syntheses" seems to have become a fairly frequent key term. For example, we find it in recent research on the professionalization of early childhood education (Havnes, 2018), and Gilje (2017), in his 
analysis of the knowledge base of an international top gymnastics coach, argues that the term encompasses episteme and techne as well as phronesis (on which it is originally based). Both publications strongly hint that practical syntheses are relevant to a distinction between practical and didactic skills, and as such the usefulness of the concept stretches way beyond Norwegian borders (see also Kvernbekk, forthcoming).

Furthermore there is no reason to think that Grimen's concept is only applicable in the professional realm of the field of education. Practical syntheses are clearly reminiscent of Myhre's map; it will be recalled that this map pictures foundational disciplines at the periphery and theories of upbringing and schooling at the center - the idea being that the foundational disciplines all should contribute to the central issues. But whereas Myhre does not say how this should happen, the concept of practical synthesis provides an idea of how it could be done: a careful selection of elements from the foundational disciplines, brought together to address a particular problem in the theory of upbringing and/or schooling, thereby creating a pocket of epistemic coherence and unity.

\section{Theoretical integration}

Grimen explicitly states that any unity in professional knowledge bases can only come from practical syntheses - the theoretical knowledge is simply too fragmented and heterogeneous to admit of any theoretical syntheses. There does however exist such a thing as theoretical integration, although it may differ from theoretical syntheses in some regards. Theoretical integration would find itself in the traditional disciplinary realm of the field of education, and might thus provide a nice counterpart to practical syntheses. For sure theoretical integration can be the home of rigor, rules and organized skepticism.

Theoretical integration is not a new invention. Traditionally philosophers of science have discussed this topic in terms of reductionism: if one theory can be reduced to another more general theory, the two are said to be integrated (e.g. Nagel, 1970). But reductionism is not a feasible strategy in modern science, and it seems more promising to discuss theoretical integration in terms of interdisciplinarity (e.g. Thorén \& Persson, 2013). We would specifically like to mention Lindley Darden and Nancy Maull's idea of an interfield theory as relevant and interesting here (Darden \& Maull, 1977). Interfield theories relate one field or one part of a field to another by postulating or establishing 
various connections between them; be they ontological, causal, conceptual, epistemic, methodological, or other. Interfield theories thus allow different fields to map onto each other. The main principle is that an interfield theory may provide answers to questions which arise in one field but which cannot be answered within that field alone, but by a coupling together of two (or more) fields. They take a field to be a relatively small and fairly well circumscribed entity, consisting of a central problem, a domain of facts and theoretical explanations - perhaps what we in our map discussions have called foundational or constituent disciplines. Recall Myhre's map with its double-headed arrows to connect the constituent disciplines. While Myhre provides no discussion or examples of how these connections are to be understood, Darden and Maull investigate four different interfield connections: One field might specify the physical location of an entity or a process postulated in another field; one field may identify the physical nature of an entity or process postulated in another field; one field may inquire into the structure of an entity whose function is inquired into in another field; and fields may be linked causally, as when entities postulated in one field provide causes the effects of which are investigated in another field.

As an example of how theoretical integration might work, let us look at socialization theory. Socialization is a highly complex phenomenon the representation of which, we argue, requires the integration of different independent theories - such that these theories together account for socialization (Darnell \& Hoëm, 1996). An adequate account of socialization requires a theory of learning at the individual level, it requires a theory of cultural transmission, and it requires a theory of social structures and their influence. These three component theories describe different entities and operate at different levels of aggregation. None of the three component theories are alone sufficient to account for socialization, and consequently socialization theory cannot be exclusively identified with either of the component theories. This is not a case of component theories providing independent perspectives on the same phenomenon; this is a case of the output of one theory, e.g. learning, becoming input to or feeding into, say societal structures, because the learning of many individuals create changes in social structure and values, which again create new opportunities of individual actions and learning. Thus, different theories are integrated. 
It stands to reason that theory integration is a complex process. It requires internal boundary-work, moving old internal boundaries, erasing some of them, erecting new ones. It has the effect of creating order and unity in some part of the field. We suggest that the field of education worldwide might benefit enormously from such efforts.

\section{Possible areas of convergence}

Finally, we would very briefly like to suggest other ways of creating pockets of order and thus combat fragmentation and disintegration.

One subfield where convergence is possible and local order might ensue, is subject didactics. As shown in the previous section, subject didactics is a substantial part of the field of education in Norway. Helga Eng's 1926 overview tells us that didactics has a long tradition as professional and systematic core element and has been part of most disciplinary maps (but not in Stafseng's map, as we have seen). From the 1970s research into didactics has been taken up by school subject specialists. The impetus came from teacher education and a growing concern that education had to be integrated into the subjects; that is, into mathematics, languages or science. These subjects have internal structures that place restrictions on how they should be taught - hence, didactics needed to interact with the nature of the subject. This presents a challenge for general didactics, which loses its character and its status as common and overarching. It also presents possibilities for renewal. More to the point, in order to counteract the drive toward further fragmentation inherent in this development, we see the establishment of new subfields such as comparative subject didactics in educational research in all Scandinavian countries (Brink \& Nilsson, 2006, Ongstad, 2012).

In a similar vein, some local mapping might occur around issues of design; a new buzzword in didactical research, with a special focus on learning and ICT. The evidence movement, and its concomitant faith in causal methodology, big data and meta-analyses, might also provide a point around which convergence might take place. 


\section{Conclusion}

Mapmaking is an old and ubiquitous human enterprise. Maps are important because they communicate overviews, connections, centers, peripheries, distances, nearness.

Boundaries both connect and divide. They are drawn to delineate not only inside and outside, but also finer distinctions inside. This requires a landscape that allows mapping, that is stable enough to allow the boundaries to make sense.

The landscape we call education is very much alive in that it keeps growing, changing, shifting, becoming ever more diversified. We have employed three Norwegian maps of education to illustrate; first, that maps are drawn; second, that they change in response to changes in the landscape; and third, how the landscape outgrows traditional mapping so that more abstract forms of mapping develop instead. To be sure this is not a Norwegian phenomenon, and the most abstract map is not only international but in sense a meta-map - it maps the basic coordinates and not the landscape because the landscape has become too unwieldy. The growth of the landscape was again illustrated with the case of Norway - we sacrificed detail for overview to show the growth of the field.

We have argued that today no comprehensive map can be had of the landscape of education in its entirety. The landscape is too fragmented and too fluid - both internal and outer boundaries are shifting, being re-worked, expanded, contracted, changed. But while no map of the whole may be possible, surely there are efforts to be made toward local unification and the taming of fragmentation.

\section{References}

Bridges, D. (2006). The Disciplines and Discipline of Educational Research. Journal of Philosophy of Education, 40, 2, 259-272.

Brink, L. \& Nilsson, R. (Eds.) (2006): Kanon och Tradition [Canon and Tradition]. Gävle: Högskolan i Gävle.

Carroll, L. (1988). The Complete Works of Lewis Carroll. London: Penguin Books.

Darden, J. \& Maull, N. (1977). Interfield Theories. Philosophy of Science, 44, 1, 43-64.

Darnell, F. \& Hoëm, A. (1996). Taken to Extremes. Education in the Far North. Oslo: Scandinavian University Press 
Eng, H. (1926). Norsk opdragelsesvidenskab 1900-1925. Norsk pedagogisk årbog 1926. Levanger

Gieryn, T.F. (1983). Boundary-Work and the Demarcation of Science from Non-Science: Strains and Interests in Professional Ideologies of Scientists. American Sociological Review, 48, 6, 781-795

Gilje, N. (2017): Profesjonskunnskapens elementære former [The elementary forms of professional knowledge]. In Smeby, J.-C. \& Mausethagen, S. (Eds), Kvalifisering til profesjonell yrkesutøvelse [Qualification for professional work] (21-33). Oslo: Universitetsforlaget.

Grimen, H. (2008). Profesjon og kunnskap [Profession and knowledge]. In A. Molander \& L.I. Terum (Eds), Profesjonsstudier [The Study of Professions]. Oslo: Universitetsforlaget

Gunnes, H. et.al. (2017). Utdanningsforskning i Norge 2015: Ressurser og resultater [Education research in Norway 2015: Resources and results]. NIFU Report no. 4, Oslo: NIFU.

Havnes, A. (2018). ECEC Professionalization - challenges of developing professional Standards. European Early Childhood Education Research Journal, 26, 5, 657673

Helsvig, K. (2003). Pedagogikkens grenser [The boundaries of the discipline of education]. Oslo: Abstrakt forlag.

Hofstetter, R. (2012). Educational Sciences: Evolutions of a Pluridisciplinary Discipline at the Crossroads of other Disciplinary and Professional Fields. British Journal of Educational Studies, 60, 4, 317-335.

Hofstetter, R., Fontaine, A., Huitric, S. \& Picard, E. (2014). Mapping the discipline history of education. Paedagogica Historica, 50, 6, 871-881.

Høgmo, A., Solstad, K.J. \& Tiller, T. (1981). Skolen og den lokale utfordring: sluttrapport fra Lofotprosjektet [Schools and local challenges: Report fram the Lofoten Project]. Troms $\varnothing$ : Troms $\varnothing$ University

Jarning, H. (2016). Det pedagogiske kunnskapsområdet og Norsk pedagogisk tidsskrift [The educational knowledge domain and The Norwegian Journal of Education]. Norsk Pedagogisk Tidsskrift, 100, 4, 247-260 
Kvernbekk, T. (2001). Om pedagogikkens faglige identitet [On the identity of education as a discipline]. In T. Kvernbekk (Ed.), Pedagogikk og larerprofesjonalitet [Education and the professionality of teachers] (p.17-30). Oslo: Gyldendal

Kvernbekk, T. (forthcoming). Practitioner tales. Possible roles for research evidence in practice. Educational Research and Evaluation

Myhre, R. (1980). Pedagogisk filosofi [Philosophy of Education]. Oslo: Fabritius

Nagel, E. (1970). The Structure of Science. Problems in the Logic of Scientific Explanation. Indianapolis: Hackett Publishing Co.

Ongstad, S. (2012). Komparativ fagdidaktikk? Eksempler, hypoteser og forutsetninger [Comparative subject didactics? Examples, hypotheses and presuppositions]. Cursiv, 9, 33-50.

Research Council of Norway (2002). Evaluering av norsk pedagogisk forskning [Evaluation of Norwegian educational research]. Oslo: RCN

Stafseng, O. (2011). Pedagogisk lærdomshistorie, en introduksjon [Introduction to the history of educational learning]. In T. Kvernbekk (Ed.), Humaniorastudier $i$ pedagogikk. Pedagogisk filosofi og historie [Humanities studies in education. Philosophy and history] (p. 89-114). Oslo: Abstrakt Forlag

Stichweh, R. (1996). Science in the system of world society. Social Science Information, $35,2,327-340$

Terhart, E. (2016). Interdisciplinary research on education and its disciplines: Processes of change and lines of conflict in unstable academic expert cultures: Germany as an example. European Educational Research Journal, 16, 4, 1-16

Thorén, H. \& Persson, J. (2013). The philosophy of interdisciplinarity: sustainability science and problem feeding. Journal for General Philosophy of Science, 44, 2, 337-355.

Trowler, P. (2014). Depicting and researching disciplines: strong and moderate essentialist approaches. Studies in Higher Education, 39, 10, 1720-1731

Tröhler, D. (2016). Die Pädagogisierung des kalten Krieges. http://orbilu.uni.lu/bitstream/10993/28728/1/80_112-BiG-Schriftenreihe-No65Kapitel-16_Tro\%CC\%88hler.pdf.

Vislie, L. (1986). Pedagogikk som fag og forskning [Education as discipline and 
research]. Oslo: RSF/NAVF

Wilford, J.N. (2000). The Mapmakers. New York: Vintage Books 